\title{
VÄITÖKSET
}

\section{Social Policies for Older Indigenous People in Taiwan}

This dissertation examines the relationship between the colonial state and Indigenous peoples by focusing on the case of elderly care. There are three things I wish to share with you in this lectio praecursoria. They not only give the key context of the dissertation, but also explain the core value of this work. The three themes are reclaiming identity, deconstructing "Indigenous problems" in policies and reconceptualizing elderly care.

\section{Journey Embarked with Reclaiming my Name}

First, I want to share with you the story of my names, which has informed my theoretical and methodological choice to re-center decolonizing perspectives in the research.

This dissertation is informed by a journey of exploring my identities and names. When I was born in Taiwan in the end of the 1980s, my parents gave me the name "Chen I-An". Chen is a surname, a family kinship marker that was obligatorily taken from my father's side; I-An means easy-going and safe. Being born during the year when martial law was lifted, it was unthinkable to have a name that showed any Indigenous heritage. I was raised with Mandarin Chinese, the national language, as my first language. My family shielded me from their own mother tongues of Hakka and Tayal, as they were afraid that I would get confused and fail to succeed in the future. In Taiwan, the children of an Indigenous woman who has married a non-Indigenous person tend to automatically lose their Indigenous identity in the population registry. It happened to my father and, consequently, to me.

Ten years later, when I started to learn English, I was given the Western name "Grace".

I continued to use my dual names - Chen I-An and Grace - when I entered high school. Tayal had become distant and foreign.

When I entered university in the 2000s, I witnessed a vibrant consciousness of the citizens in Taiwanese society waking up, and the trend of recognizing difference was in full swing. I started to consider changing my name as an acknowledgement of my Indigenous heritage. I felt safe to do it at the university, as I thought nobody would sneer at me there. I also reclaimed my Indigenous status after my father reclaimed his by updating our family name from Chen to Gao in the national registration system. Gao is my grandmother's last name, which she received through a randomized lottery system from the Chinese district registration office when she was a child. Like many people of her generation, she used to have a Japanese-sounding name and not a typical Tayal name. People in the community call her Huzi.

Grandma Huzi gave me the Tayal name Wasiq. It refers to a delicious, common and important plant in the community. There is no family name in the Tayal system. Instead, my grandmother taught me that we use our father's or mother's name attached to our own names to distinguish whose sons or daughters we are. In my case, my father's indigenous name is Silan, so I should refer to myself as Wasiq Silan. However, I kept quiet about being Wasiq Silan. 
When I was small, I simply did not know enough to care about this Tayal heritage. As I grew up, this ignorance was replaced by a sense of guilt. For the most part, I thought that I am not Tayal enough - I have constantly been asked how pure I am (how much Indigenous blood I have) and told that I do not look "Indigenous" (implying that I am too pale). Most importantly, I felt that it was fake to claim that I am Tayal without being able to speak the language or tell a proper joke with the proper accents, or when not living in the community on an everyday basis.

But then, through speaking with friends and colleagues about my research and my identity, it gradually dawned on me, like raindrops that finally make their way back to earth, that those things - bloodline strength, familiarity with the culture, language proficiency or appearance - are not what qualify whether I am Tayal or not. Colonialism and assimilation had done their work. The language was washed from my Tayal mouth, and the community that was once strong, autonomous and proud was scattered. I was stunned that I almost let colonial logic succeed in washing away my commitment to being Tayal. It came to me that it is more about negotiating an Indigenous identity for myself and staying committed to that process. In other words, being Indigenous is an active process of becoming, and it is based on this process of becoming that I have written my dissertation. This is the first key theme here. This thesis is not the only thing that came into being through six years of work. This research has also breathed life into my identity as a Tayal.

\section{Reframing Elderly Care Policies from the Indigenous Perspective}

This transformation compels me to follow a path walked already by many Indigenous researchers. This is my second theme: exploring the intersection of two powerful worlds, the world of research and the world of Indigenous peoples. Exploring these worlds at the intersection of social policy for the elderly, I found out that no matter how multicultural Taiwan may seem, the view on indigeneity still operates through binaries of civilized versus barbaric, knowing versus ignorant, and deserving versus undeserving.

In my dissertation Social Policies and Indigenous peoples in Taiwan: Elderly care among the Tayal, I discuss social policies and their impact on Indigenous peoples. Social policies are supposed to improve and reform society - it is said that social policy is a study of the causes of social problems and the government's attempts to do something about them. Nevertheless, both state policies and political science carry a colonial legacy that they still need to address and work on. This is urgent, as Indigenous peoples continue to be framed as the policy problem itself, and blamed for not accepting the terms of their colonization. From the Indigenous perspective, the goal that social policies want to achieve - improving society - remains a distant and audacious dream. Maori researcher Linda Tuhiwai Smith (2012, 94-95) points to the making of the "Indigenous problem" as recurrent in all imperial and colonial attempts to deal with Indigenous peoples, a Western obsession. My thesis seeks to confront the tendency to treat Indigenous people as mere research objects with lots of problems. This colonial legacy of research, which can permeate policies, continues to impact many Indigenous lives. I asked my grandmother why the government gave us subsidies when it realized we were Tayal, since we had changed our family name to Gao. She hesitated and asked, "I don't know. Is it because we the Tayal don't have money? Or is it because Indigenous people are stupid?" Her questions echoed a wound that was invisible to me before I reclaimed my identity. It was a learned sense of discouragement and despair, communicated to her generation that they were the problem.

Experiences like this compel me to further develop Tayal hermeneutics, a research 
agenda built on the knowledge standpoint that privileges Tayal epistemology. As a Tayal researcher, I use Tayal hermeneutics as a catalyst for analyzing theories and findings as a political act against the type of objectifying research that has made Indigenous peoples "dispossessed". A lot of research concerning the Tayal has been conducted, but not with them or from their point of view, not to mention in their interest of community development. Engaging with what elder Wille Ermine (2007) has called "ethical space", I developed a visual representation of my research process as a Tayal researcher. Grounded in collaboration, the visual representation signifies a conceptual storyboard of decolonization, from indigeneity to the disruption of coloniality, to Tayal hermeneutics and Indigenous research paradigm as a remedy, then elevating Indigenous knowledge in ethical space, ultimately re-indigenizing back to our roots (Silan 2022).

Drawing from Bacchi and Verloo, my thesis views policy as not solving problems, but creating problems (Bacchi 1999; Verloo \& Lombardo 2007). By defining the problem, policy also gives shape and meaning to the problematics, and in so doing creates the form in which the problem is interpreted. This stance is useful, as it helps to examine the conceptual prejudices embedded in making the social policy.

One dominant prejudice is Indigenous authenticity. During the course of my research, there has been increasing policy pressure to make day clubs for the elders "go tribal". I learned that many Tayal have struggled with this demand of indigenous authenticity. I sensed anxiety when I sat side by side with the Tayal women who worked as care workers back in the community, and who scratched their heads and tried to come up with activities for the bnkis, or Tayal elders, that would qualify as "tribal". I witnessed the same frustration among the bnkis, who exclaimed that they were not able to speak Tayal anymore, after linguists harshly criticized them for speaking "inauthentic Tayal". This anxiety is fueled by policy that reinforces the supposed desirable way of being a Tayal.

\section{Reconceptualizing and Envisioning an Alternative Version of Care}

The third theme that I wish to address in this presentation is reconceptualizing elderly care.

In the policies, care is often framed as a one-size-fits-all, standardized means and tool to prevent physical decay. In my study, the day clubs have been mandated to go "tribal" as a way to better promote active aging. In contrast, the stories of the Tayal show that how policies treat "tribal" as just another flavor is problematic, as it ignores imbalanced power relations and inflicts further colonial trauma on the bnkis. Care should be conceptualized as broad-based, non-fragmented, inter-relational and wholistic. Tronto and Fisher (1990) suggest that care is an activity that helps us to "maintain, continue, and repair our 'world' so we can live in it as well as possible". My dissertation affirms that for the bnkis, care is not a tool to a desired end, but an indispensable process in itself. Care is living well when we see it as a process, which entails an ethical responsibility and a reciprocal commitment to the community.

The well-being of Indigenous peoples should not be culturalized or simplified as merely a language problem. Indeed, providing services in the Indigenous languages is key. In ongoing social and health care reform in Finland, many Saami activists have expressed concern about whether the reformed service can ensure that the linguistic and cultural background of the patient will be taken into account. Yet, the problematic representation of narrowly treating increased cultural safety as promoting the linguistic ability of the care workers may risk ignoring the Indigenous perspective of care, which is relational, ecological, contextual, 
situational and intergenerational. It may treat Indigenous language as a tool to promote oneon-one, contract-based, commodified care service under the logic of neoliberalism.

The vision that emerges from the analysis in this dissertation is one of many suppressed voices of living and caring. Aging is not chronological decay when the diverse meanings embedded in it can be cherished. Aging is not a progressive loss, but a progressive enrichment. The aged are not only recipients of care; in order to be complete, they need to be given opportunities to care as well. Responsibility and reciprocity are an indispensable part of the different stages of life.

Becoming a Tayal is about reclaiming my name, reframing social problems, relearning the language, and recommitting to the Tayal philosophy and onto-epistemology. I am privileged to have the opportunity to breathe life into the Tayal way of seeing, speaking, being and becoming.

This doctoral project brought me 8000 kilometers, from Taiwan to Finland. Toward the end, I have realized that it has also brought me home.

\section{References}

Bacchi CL. Women, policy and politics: the construction of policy problems. London: Sage, 1999.

Ermine W. The ethical space of engagement. Indigenous Law Journal 2007;6(1):193-203. https:// jps.library.utoronto.ca/index.php/ilj/article/ view $/ 27669 / 20400$

Silan W (Gao IA). Social policies and Indigenous peoples in Taiwan: elderly care among the Tayal. Publications of the Faculty of Social Sciences 186, University of Helsinki. http://urn.fi/URN:ISBN:978-951-51-7006-4

Silan W. Tayal epistemology based on the Tayal elders at a day club. Manuscript in preparation, to be published 2022 .
It is with this gratitude that I end the lectio with a song of gratitude in Tayal.

Kinholan na Tayal,

Maras insuna tayal

Utux kayal yaba ta

Mlahang ita na Tayal

Our ancestral origin

With ancestors' breath and blessings

Spirit of our father in the sky

Looking after us

Thank you all. Mhway simu kwara.

Wasiq Silan, D.Soc.Sc.

an.gao@helsinki.fi

The dissertation "Social Policies and Indigenous Peoples in Taiwan: Elderly Care Among the Tayal" was defended at the Faculty of Social Sciences of the University of Helsinki on 18 May 2021.

Valtio-opin alaan kuuluva väitöskirja "Social Policies and Indigenous Peoples in Taiwan: Elderly Care Among the Tayal" tarkastettiin Helsingin yliopistossa 18.5.2021.

Smith LT. Decolonizing methodologies: research and indigenous peoples. 2nd ed. London: Zed Books; University of Otago Press, 2012.

Tronto JC, Fisher B. Toward a feminist theory of caring. In Abel E, Nelson M, eds. Circles of care. Albany, NY: SUNY Press, 1990:36-54.

Verloo M, Lombardo E. Contested gender equality and policy variety in Europe: introducing a critical frame analysis approach. In: Verloo M, ed. Multiple meanings of gender equality: a critical frame analysis of gender policies in Europe. New York: Central European University Press, 2007:21-51. 